\title{
Enhanced patient involvement in Swedish aphasia intervention
}

\author{
Charlotta Plejert, Christina Samuelsson and Jan Anward \\ Journal Article
}

\section{Tweet}

N.B.: When citing this work, cite the original article.

This is an electronic version of an article published in:

Charlotta Plejert, Christina Samuelsson and Jan Anward, Enhanced patient involvement in Swedish aphasia intervention, Clinical Linguistics \&amp; Phonetics, 2016. 30(10), pp.730748.

Clinical Linguistics \& Phonetics is available online at informaworldTM: http://dx.doi.org/10.1080/02699206.2016.1208274

Copyright: Taylor \& Francis: STM, Behavioural Science and Public Health Titles http://www.tandf.co.uk/journals/default.asp

Postprint available at: Linköping University Electronic Press

http://urn.kb.se/resolve?urn=urn:nbn:se:liu:diva-132563

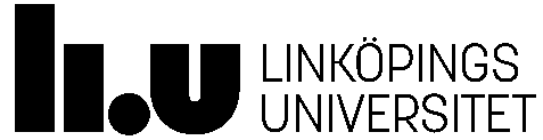


Published in Clinical Linguistics and Phonetics

http://www.tandfonline.com/action/doSearch?AllField=Plejert\&SeriesKey=iclp20.

Published online 13 Sept. 2016.

\title{
Enhanced patient involvement in Swedish aphasia intervention
}

\section{Charlotta Plejert, Christina Samuelsson and Jan Anward}

\begin{abstract}
The present article is a case-study in which participation is investigated in terms of the use of interactional practices that enhance the involvement of a man with severe aphasia in activities that aim to capture his and his wife's experiences of everyday communication, and their views of his speech and language intervention. Five practices are identified: 1) collaborative telling, 2) formulations, 3) yes/no questions, 4) declaratives, and 5) hint-and-guess strategies. It is demonstrated how participants' (wife, a speech and language pathologist, and two research assistants) use of these practices are beneficial for making the viewpoints of the man with aphasia come across, despite his communication difficulties. Results are discussed in light of the importance of finding ways to make patients influence their own intervention, both in terms of a raised awareness of facilitative interactional practices, and of activities, such as interviews and retrospection sessions with patients and their significant others.
\end{abstract}

Keywords: aphasia, conversation analysis, participation, patient involvement, retrospection

\section{Introduction}

The present article is a case-study in which participation is approached in terms of the possibilities for people with aphasia and their significant others to influence the goals of their speech and language intervention. Participation will here thus be viewed as a matter of patient involvement and engagement (Dalemans, de Witte, Wade and van den Heuvel, 2010), and discussed in terms of how the viewpoints of people with aphasia may be captured, despite difficulties associated with their condition since it affects the possibilities to get their views across. 
Published in Clinical Linguistics and Phonetics

http://www.tandfonline.com/action/doSearch?AllField=Plejert\&SeriesKey=iclp20.

Published online 13 Sept. 2016.

Research shows that patients who actively engage in their treatment, often also perceive that their quality of life is improved, and may sometimes recover more quickly (SorinPeters, McGilton and Rochon, 2010). A key feature of efficient intervention is the establishment of goals (Worrall, Sherratt, Rogers, Howe, Ferguson and Davidson, 2011). Patients' appreciation of the intervention, and their engagement and responsibilities are increased if patient and therapist mutually establish treatment goals (McClain, 2005). This is in line with directions that promote independence, and individuals' right to influence the healthcare they receive, i.e. healthcare should be patient focused (Coulter, 2002). Similarly, the social model of disability has been applied within the field of aphasiology, stressing the fact that people with disabilities "are experts in their own conditions” (Byng and Felson Duchan, 2005: 907). The viewpoints and needs of people with disabilities should thus form the basis for intervention. For people with aphasia, however, it may at times be difficult to discuss and establish intervention goals together with their speech and language pathologist (SLP), due to the communicative disability (Kagan, 1998; Simmons-Mackie, Kagan, Christie, Huijbregts, McEwen and Willems, 2007). There are, however, studies that describe strategies to enhance communicative participation and opportunities to influence treatment for a range of clinical groups (Beringer, Tönsig and Bornman, 2013; Kagan and Leblanc, 2002). For people with aphasia, it has been shown that they may be able to participate in interaction more efficiently in institutional as well as home settings, if a trained communication partner is also involved in the interaction (Eriksson 2015; Laakso, 2015; Simmons-Mackie, Raymer, Armstrong, Holland and Cherney, 2010). Although research highlights the importance of enhancing patient involvement, only a few studies discuss how this can be conducted, particularly with a focus on people with aphasia (Rautakoski, Korpijaakko-Huuhka and Klippi, 2008). There are, however, numerous studies that target participation in everyday-life activities, and quality of life for people with aphasia using interviews, questionnaires, diaries, and/or surveys as a basis 
Published in Clinical Linguistics and Phonetics

http://www.tandfonline.com/action/doSearch?AllField=Plejert\&SeriesKey=iclp20.

Published online 13 Sept. 2016.

for investigation (e.g. Dalemans et al., 2010; Hilari, Byng, Lamping and Smith, 2003). Although these studies provide very important insights concerning viewpoints and self-reports of people with aphasia and their significant others, there are few studies that investigate the actual practices and actions of participants in interaction that may enhance their involvement in relation to intervention goal-setting. Practices in interaction that are beneficial for coconstruction of meaning involving people with aphasia have been captured in numerous studies (e.g. Goodwin, 1995, 2003; Purves, 2009; Simmons-Mackie, Kingston and Schultz, 2004), but not with a specific focus on patients' and their partners' experiences of mundane communication, and of intervention. With this as a background, the present article is a casestudy involving a Swedish man with global aphasia and apraxia of speech. The aim is two-fold. Firstly, we explore the interactional practices that participants employ in order to facilitate the involvement and engagement of the man with aphasia in multiparty clinical activities, despite his communication difficulties. Secondly, we highlight his involvement in the activities per se, a semi-structured interview and a video-based retrospection session, since they deal with capturing the viewpoints and experiences of him and his wife concerning language and everyday communication after his stroke, and the goals of his intervention.

\section{Speech and language intervention for people with aphasia}

The primary goal of speech and language intervention for people with aphasia is to improve their abilitiy to communicate (Basso and Caporali, 2001). Aphasia intervention may be either symptom-based or functional (e.g. Ahlsén, 2006; Basso, 2010). In the case of the former, symptoms are viewed as the result of damage to one or several components in the cognitive system (Basso, 2010), and the goal of symptom-based intervention is to improve the language impairment that occurred due to the damage of a specific component. In the latter case, intervention is focused on enhancing and preserving the patient's ability to communicate in 
Published in Clinical Linguistics and Phonetics

http://www.tandfonline.com/action/doSearch?AllField=Plejert\&SeriesKey=iclp20.

Published online 13 Sept. 2016.

everyday situations. An example of a functional approach is Supporting Partners of People with Aphasia in Relations and Conversation (SPPARC; Lock, Wilkinson and Bryan, 2001a; Lock, Wilkinson, Bryan, Maxim, Edmundson, Bruce and Moir, 2001b). Within this program, participants video record interaction in their home environments, which subsequently form a basis for the design of intervention. This intervention is thus not only focused on the individual with aphasia, but also strongly dependent upon the involvement of significant others. Research has demonstrated that individually adapted consultations, based on Conversation Analytical (CA) principles may positively change the communication situation for persons with aphasia (Beeke, Johnson, Beckley, Heilemann, Edwards, Maxim and Best, 2015). This finding gets further support from a research review on CA-informed aphasia interventions (Wilkinson, 2014) highlighting the benefits of this approach in relation to the everyday communication needs of people with aphasia and their significant others. It is with this functional direction that the present study aligns.

In Sweden, a systematic use of intervention that is focused on social interaction is not yet firmly established. By and large, goals of speech and language intervention in Sweden still seem to primarily be based on formal tests of the patient's linguistic ability, and focus on the areas that the patient has particular difficulties with, as demonstrated by these tests. The same seems to be true also in other Nordic countries, for example Finland (Klippi, Sellman, Heikkinen and Laine 2012). The outcome of the intervention is mainly measured in terms of improved test results over time, and after a certain amount of intervention. Instruments to assess if features practiced in intervention are carried over to everyday language use (Samuelsson and Plejert, 2015) are rarely used.

It may be argued that already the overall design of most function-directed interventions and approaches is affected by the fact that participants are to be actively involved to as great an extent as possible. However, the actual involvement of patients themselves is 
Published in Clinical Linguistics and Phonetics

http://www.tandfonline.com/action/doSearch?AllField=Plejert\&SeriesKey=iclp20.

Published online 13 Sept. 2016.

rarely the target of the intervention or study, but rather various practices and actions by a patient, and one or several significant others, and how these can be adjusted in different ways in order to enhance communication more generally. Exceptions are a study by Horton, Howell, Humby and Ross (2010), and Simmons-Mackie et al. (2004). The former investigated the involvement of patients in different stroke rehabilitation activities (speech and language intervention, physiotherapy and occupational therapy), demonstrating how patient engagement was enhanced or hindered by means of various interactional practices, for example instructions and explanations given by the health care provider in relation to the activity at hand. The latter (Simmons-Mackie et al., 2004) explored interaction between a woman with severe aphasia and a non-aphasic speaking-partner in terms of "participant frames", which is comparable to Goffman’s (1981) “participation framework”. Simmons-Mackie et al. (2004) demonstrated how the woman utilized certain interactional resources that encouraged the speaking-partner to become "animator" (Goffman, 1981) of what she aimed to convey. Their findings are particularly relevant in relation to this study's aim of exploring the ways in which the person with aphasia is able (or not) to actively participate in the activities that deal with his everyday communication needs, and the goals of his intervention.

\section{Participants, material, and method}

The data used in the present study were collected within the research project Interaction and Intervention. People with communicative disabilities in clinical and everyday interaction (VR 2010-1440), in which the relationship between goals of speech and language intervention and patients’ everyday communication needs was investigated.

Table 1 below, presents information on the participants, Olle, a man in his 60s, his wife Eva, two research assistants (A1 and A2), and an SLP. Information about the patient's 
Published in Clinical Linguistics and Phonetics

http://www.tandfonline.com/action/doSearch?AllField=Plejert\&SeriesKey=iclp20.

Published online 13 Sept. 2016.

diagnosis and language characteristics was obtained from his medical records. All names in tables and transcription excerpts are fictitious.

[Insert Table 1 about here]

The material consists of a video-recorded, semi-structured interview with Olle and his wife about their perception of language and communication after aphasia onset (e.g. what they find difficult and what they find easy), and an audio-recording of a video-based retrospection session, in which participants watch and discuss short video-clips of their communication from everyday settings and speech and language intervention that had been recorded on a previous occasion (cf. Samuelsson and Plejert, 2015, for the same procedure involving children with language impairment). During retrospections, participants were asked to spontaneously comment on anything of interest to them. The research assistants had also identified points of interest beforehand, to be discussed.. In this respect, the retrospection sessions may be described as semi-structured. Table 2 provides an overview of the audio-visual material used for the purpose of the present article. The total length of the recordings investigated is $1 \mathrm{~h} 24$ $\min 68$ sec.

\section{[Insert Table 2 about here]}

It should be mentioned that the two research assistants, who were both students at their final stage of SLP training, were not involved in Olle’s intervention. Their participation took place within the framework of the larger research project, in which their task was to conduct interviews and retrospection sessions.

The methodology used in the present study is CA (e.g. Sidnell and Stivers, 2013), and transcriptions follow the Jefferson conventions (2004) found in the introduction to the issue, with some adaptations, i.e. capital letters are neither used in the beginning of turns nor for new turn-constructional units, and only the vowel is underlined in syllables that are stressed or otherwise emphasized. 
Published in Clinical Linguistics and Phonetics

http://www.tandfonline.com/action/doSearch?AllField=Plejert\&SeriesKey=iclp20.

Published online 13 Sept. 2016.

\section{Results}

Analyses identified five practices by which the involvement of Olle was facilitated based on Olle's actions in concert with the actions of his interlocutors: 1) collaborative telling, 2) formulations, 3) yes/no questions, 4) declaratives, and 5) hint-and-guess strategies. These practices were also accompanied by non-verbal resources and temporal aspects, which are commented on when relevant. Since the different practices were often used together, the presentation below is organized in sections based on the different activities in which the practices occurred. Each excerpt is then named in accordance with what practice, or practices are in focus. Excerpts 1-4b are used as show-cases. In excerpts 1 and 2, participants are engaged in talking about Olle's and Eva's experience of language and communication after the stroke. Excerpts 3a-4b occur when participants discuss Olle's intervention, and what Olle and Eva would like to continue working on.

Talk about experiences of language and communication after Olle’s aphasia onset

In Excerpt 1, Olle (O) and Eva (E) are interviewed and asked questions by the research assistants (A1 and A2) about what language and communication have been like since Olle's stroke . Translation into English is provided in italics and shaded in grey. Minimal responses are not translated unless needed.

\section{Excerpt 1: Collaborative telling}

01 A2: (ja gör så där) e va va tycker du e svårast me talet äre att

○2 (๑.4) att kunna uttrycka ((at this point 0lle looks upwards in a "thinking face"))(0.6) e: : tankar eller äre att (0.5) förstå

03 (०.3) va andra (0.6) säger också

( I do like that) e what what do you think is most difficult with speech is it to (๑.4) to express ((at this point olle looks upwards in $a^{\prime \prime}$ thinking face")) (०.6) thoughts or is it to (0.5) understand (0.3) what others $(0.6)$ say too.

$04 \quad(0.5)$

05 0: $\quad n *$ hä* ja: : = ( (looks forward and a bit down and shakes head slightly)) 
Published in Clinical Linguistics and Phonetics

http://www.tandfonline.com/action/doSearch?AllField=Plejert\&SeriesKey=iclp20.

Published online 13 Sept. 2016.

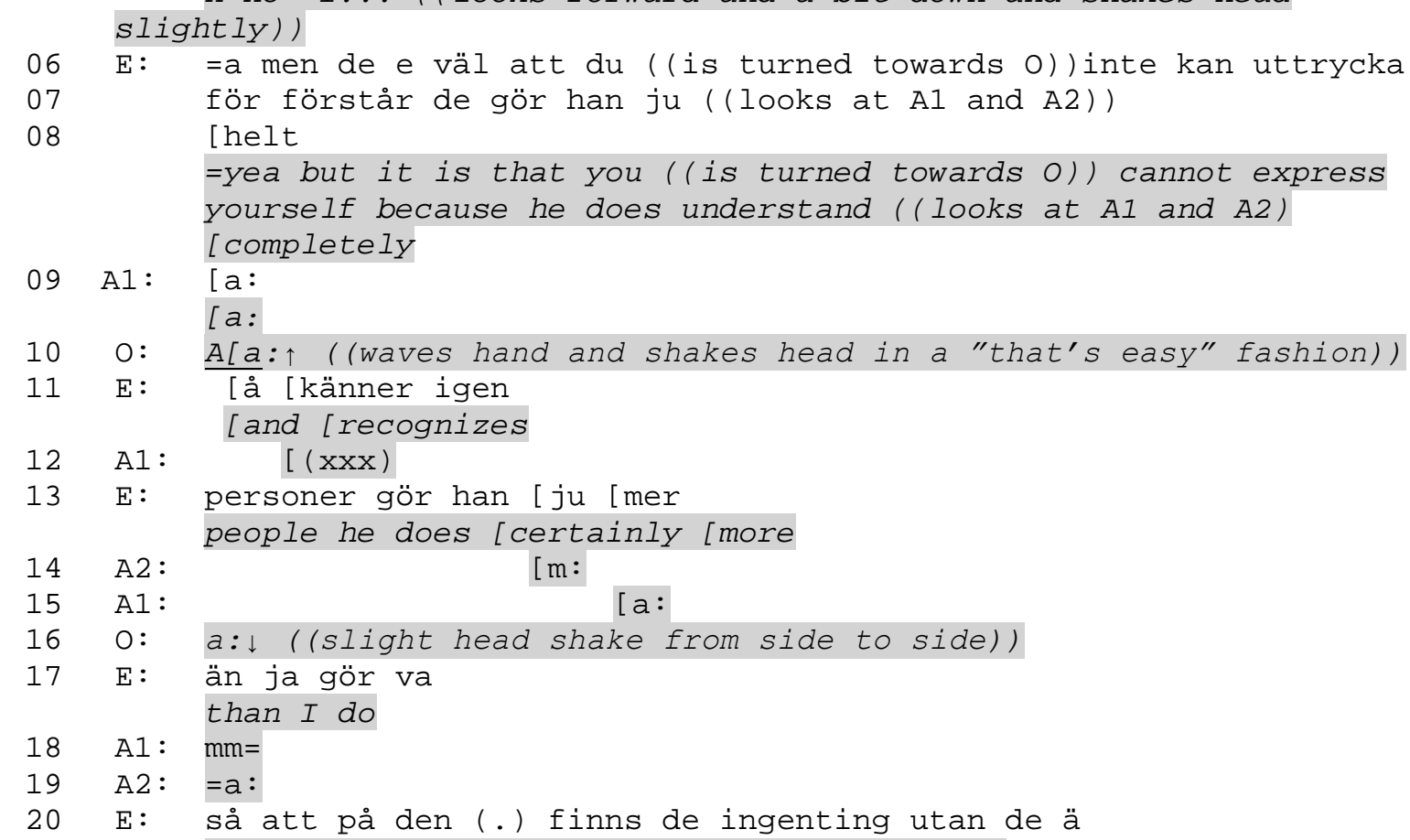

The participants are sitting at a table in a room in the SLP clinic. A2 asks a multi-unit question (Linell, Hofvendal and Lindholm, 2003) where the first part deals with what is difficult with speech generally (line 01), immediately followed by two candidate answers in terms of expressive and receptive skills (lines 02, 03). When asking this question, A2 is looking at Olle, and the use of the second person singular pronoun "du" (you) clearly signals that the question is asked to him specifically. When asked the question, Olle initially looks attentively towards A2; and then, as A2 says "uttrycka” (express) (line 02) he leans his head slightly backwards, looks upwards in a "thinking face” (Goodwin and Goodwin 1986:57ff) which continues during the remaining part of the question. There is a brief pause (line 04), and Olle then bends his neck forward and looks down shaking his head slightly at the same time as he says "n*hä*” (no) with a touch of embarrassment and laughing voice (Wilkinson, 2007) followed by “ja::” (yea), which is one of Olle's few verbal resources. During A2's question, Olle’s wife has primarily been looking at A2, but as the question moves towards its end, she turns her gaze towards Olle, 
Published in Clinical Linguistics and Phonetics

http://www.tandfonline.com/action/doSearch?AllField=Plejert\&SeriesKey=iclp20.

Published online 13 Sept. 2016.

seemingly perceiving that he does not manage to verbalise an answer on his own. Immediately (line 06), she proposes, initially directed towards Olle, that the main problem is a matter of expression, and then redirects her gaze towards A2 and A1 as she states that Olle understands, now talking about him in the third person "han” (he). This practice of speaking on behalf on someone else may be perceived as negative and diminishing for the person with limited skills. However, research shows that it is important who it is that performs this action, and that a shared history may turn it into an opportunity for couples to collaboratively construct, for example a story (Goodwin, 2004; Purves, 2009). Here, it appears to be Eva's way of putting words to what she presumes that Olle thinks in relation to A2's question, which actually only offers two alternatives that she knows equally well as Olle, since they share the experience of his communicative problems. It should be noticed also that she does not formulate the answer as a definite one initially, as she "invites" the viewpoint of Olle, by using the modal particle "väl”, which modulates the degree of certainty of her expression (Lindström, 2008). Olle expresses his alignment with this answer both verbally with a confirming "Aa: $\uparrow$ " (Yea) and non-verbally by waving his right hand and shaking his head in a “that's easy” fashion. Eva then elaborates on the issue of Olle's competence in terms of stressing that he even recognizes people better than she does herself (lines 11, 13,17), and again, her account is complied with by Olle, who produces a supportive “a: $\downarrow$ "(line 16). It is important to point out that Olle's contributions in terms of supportive feedback occur in a perfectly orchestrated fashion with Eva's turns, thus making this a collaboratively and mutually agreed-upon account of their experiences (Simmons-Mackie et al., 2004), in relation to the question asked by A2.

Another representative example of collaborative telling is presented in Excerpt 2. It is followed by a formulation by one of the assistants.

\section{Excerpt 2: Collaborative telling and formulation}

$01 \mathrm{E}$ : S som ja upplever't så har han ju ordena fast han (0.2) 
Published in Clinical Linguistics and Phonetics

http://www.tandfonline.com/action/doSearch?AllField=Plejert\&SeriesKey=iclp20.

Published online 13 Sept. 2016.

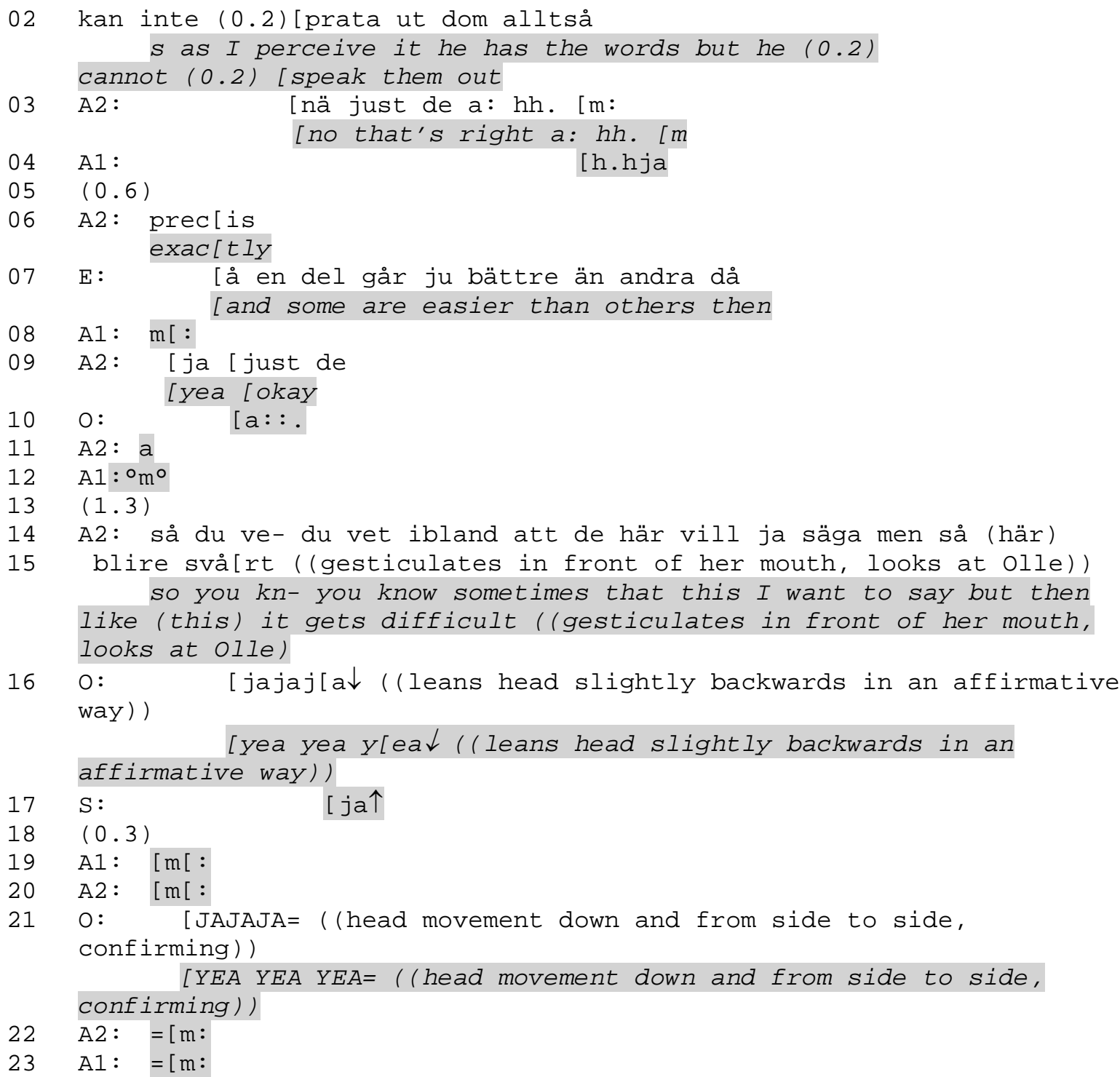

Eva is describing how she perceives Olle's linguistic ability in terms of having the words, but not being able to produce them (lines 01,02 ). This account is acknowledged by both A2 and A1 (lines 03, 04, 06). Then she also states that some words appear to be easier for Olle than others (line 07). Olle is actively engaged in what Eva is saying, and also nods and produces a confirmatory response (line 10) to Eva's statement about the differences between words (line 07). Consensus seems to have been reached, and a new topic might have been initiated at this point. However, after a pause (line 13), A2, attempts to capture the gist of what has been brought up by Eva so far, using a formulation (Heritage and Watson, 1979), and turns towards 
Published in Clinical Linguistics and Phonetics

http://www.tandfonline.com/action/doSearch?AllField=Plejert\&SeriesKey=iclp20.

Published online 13 Sept. 2016.

Olle to check if he accepts the offered version (lines 14, 15). As in Exerpt 1, she uses "du” (you). She also makes a gesture with her hand in front of her mouth as part of the formulation, possibly illustrating difficulties producing words. Olle expresses his agreement initially saying “ja ja ja $\downarrow$ " (yea yea yea), with an affirmative facial expression. A2 checks for further confirmation (line 17), and Olle upgrades his prior answer by increased loudness and nodding and turning his head from side to side (line 21). He clearly demonstrates his agreement with the statement that he knows what he wants to say.

In both excerpts from the interview with Olle and Eva, despite the fact that Olle is limited in what he can express verbally, participants have mutually managed to reach an agreement about aspects of communication that both Olle and his wife appear content with. A2's way of making an interpretation of Eva's accounts, yet turning directly towards Olle for confirmation, is an efficient means for positioning Olle as accountable and competent.

\section{Talk about speech and language interventions}

Throughout the data, A2 transforms open-ended questions into ones that may be answered by yes or no. An example of this phenomenon is presented in Excerpt 3a, when participants are engaged in talk about Olle's intervention. Olle and Eva have just shown A1 and A2 some of the exercises that Olle works on in intervention. They consist of pictures and words to be combined into short units for everyday use, e.g. "vill ha kaffe” (want coffee). There are also photos of significant persons, e.g. their son. A2 asks Olle how he feels about his exercises.

\section{Excerpt 3a: Yes/No questions}

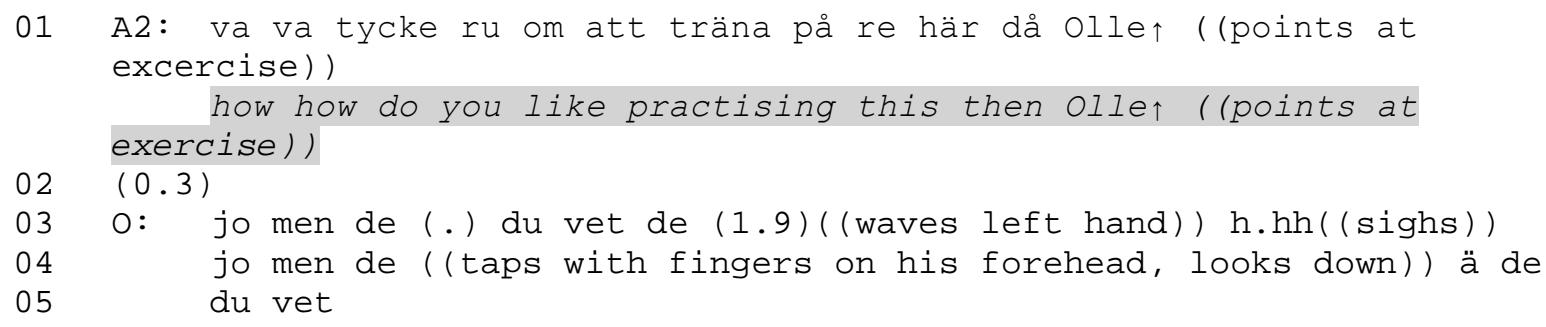




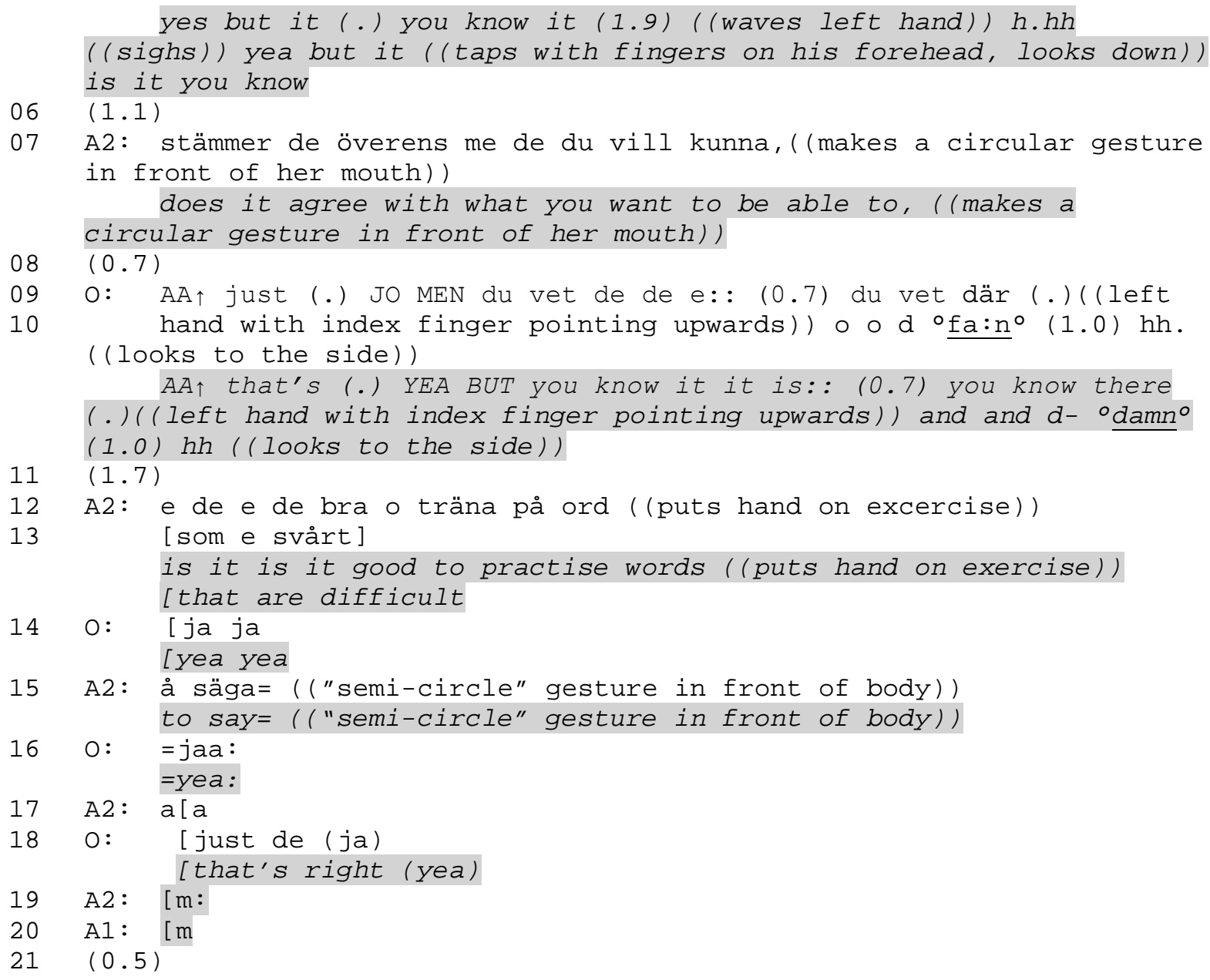

A2's initial question (line 01) might be answered in both minimal and more elaborated ways. In contrast to providing candidate answers to choose from (cf. Excerpt 1), A2 pauses and awaits Olle’s answer. Olle responds using the phrases "jo men de" (yea but it) and “du vet de" (you know it), but experiences production difficulties (lines 03, 04, 05). His attempts are accompanied by gesticulations with his left hand, first waving (line 03), and then tapping with fingers on his forehead (line 04), a gesture that he uses repeatedly when he has word-finding difficulties. Repetitions, a long pause, and a deep sigh, signal his production difficulties as well as his frustration with not being able to get his view across. Interestingly, Olle’s wife Eva (in contrast to Excerpt 1), does not offer any suggestions concerning her husband's feelings about the exercises, but leaves him to answer the question himself. This may be due to the fact that his work at the SLP's is less of a mutual endeavour than the more general aspects of 
communication that have previously been discussed. Even if her silence in some respects makes his inability to provide an immediate answer to the question surface (Lindholm, 2008), it also treats him as a person with epistemic primacy (Heritage, 2013) regarding the topic, and competent to answer, even if it is effortful. Throughout, she looks attentively at him, as do A1 and A2. In order to facilitate an answer from Olle, A2 reformulates her question, and turns it into a yes/no question (line 07). The unit is not prosodically complete, and thereby projects a main verb such as "säga” (say), but instead of a verb, A2 completes the unit with a circular gesture in front of her mouth (line 07). Olle responds positively with a loud voice, again using the fixed phrases that he regularly utilizes. This is accompanied by a pointing gesture and he looks enthusiastically towards A2 and A1. However, he gives up, and he finishes his turn with a curse "fan" (damn) and a sigh, looking towards the side. A2 attempts a new yes/no question, which is slightly reformulated so that it offers a somewhat altered meaning for Olle to confirm or reject (line 13), which he does (line 14), before A2 herself also completes the unit (line 15). Olle agrees to the suggestion made by A2 (lines $14,16,18$ ) with mutual feedback from both A2 and A1 (lines 19, 20). This could have been an ending of the topic. However, participants are all oriented to Olle as primary speaker (all three are looking attentively at him), and he continues with an account about his problems. This continuation is described in Excerpt 3b.

\section{Excerpt 3b: Formulations}

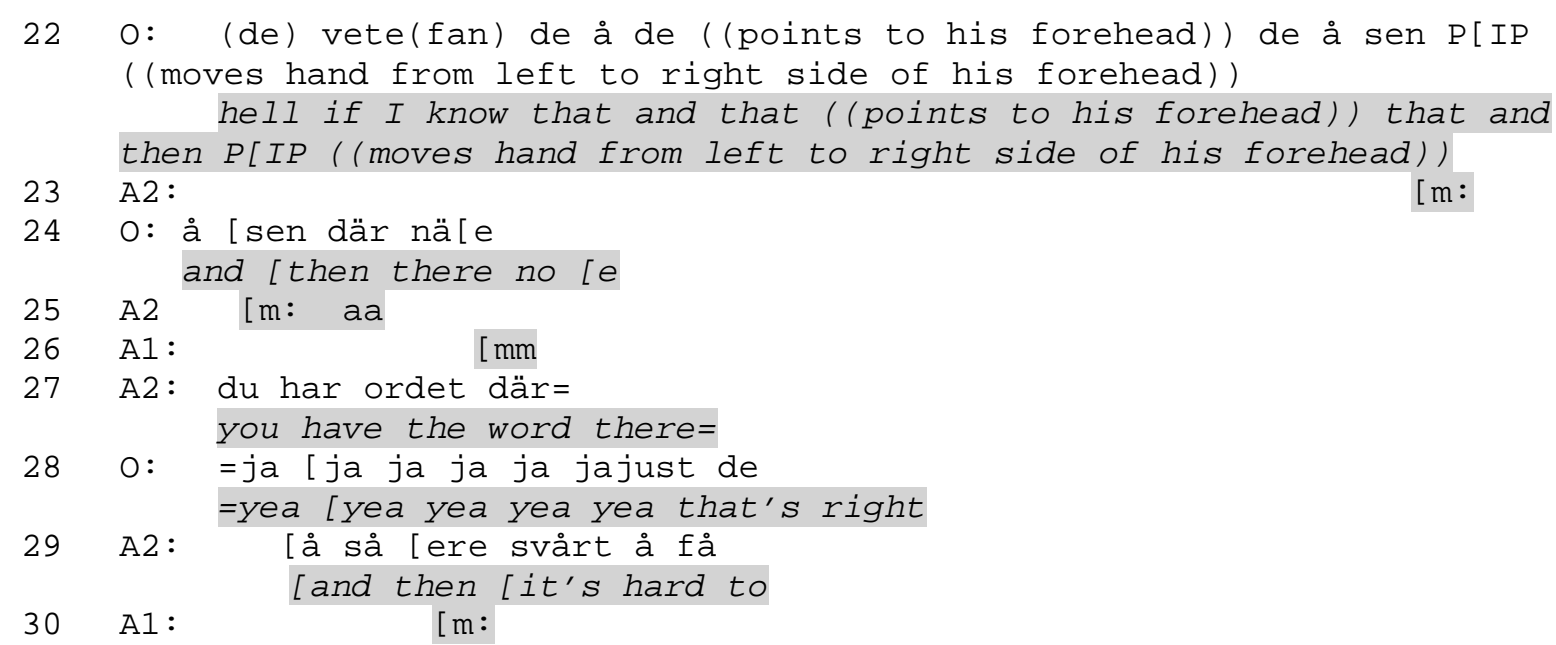


Published in Clinical Linguistics and Phonetics

http://www.tandfonline.com/action/doSearch?AllField=Plejert\&SeriesKey=iclp20.

Published online 13 Sept. 2016.

31 A2: tag på [de

32 A1: $\quad[\mathrm{h} . \mathrm{h}$

33 0: [ja just de

[yea that's right

Olle takes the initiative to continue talking, and elaborates on his production difficulties (line

22). He uses the verbal resources available to him, which in this case is the phrase "(de) vete fan” (hell if I know), and the deictic expression “de å de” that and that, which is synchronized with a pointing gesture towards his forehead. This gesture is modified and turned into a move from the left to the right side of his forehead as he says "å sen PIP” (and then PIP), as if something was erased. This is followed by a further description (line 24), which is minimally responded to by A2 and A1. A2 then makes an interpretation of Olle's account and offers a formulation in an attempt to get at the core of what he said in his prior turns (line 27), which he immediately and energetically confirms (line 28). She adds to her suggested understanding in terms of the difficulty of accessing the word (lines 29, 31), which is supported by Olle. Again, A2 has offered interpretations of Olle's own verbal as well as non-verbal accounts, which Olle may confirm or reject, which he also does in a timely and engaged fashion (cf. Heritage and Watson, 1979, concerning how formulations make confirmations or disconfirmations conditionally relevant). For the whole of Excerpt 3 (a,b), it is noticeable that A1, A2, and Eva, are all positioning Olle as main speaker, awaiting his contributions, and they do not interfere until he has finished a turn. It may be assumed that Olle might want to say a lot more than what comes out from A2's formulations. However, the fact that Olle is offered time and space to elaborate on a topic, appears to facilitate his engagement, and he does provide an account of how he experiences the aphasia.

In the following two excerpts (4a, 4b), Olle's SLP gets involved during a retrospective session about Olle's intervention. Participants have just watched a video clip in which Olle and Eva are discussing the usefulness of Melodic Intonation Therapy (MIT; Albert, 
Published in Clinical Linguistics and Phonetics

http://www.tandfonline.com/action/doSearch?AllField=Plejert\&SeriesKey=iclp20.

Published online 13 Sept. 2016.

Sparks and Helm, 1973), which is part of Olle’s current intervention. After watching the clip,

A1 asks Olle's SLP about her viewpoints of the method. In addition to the ways in which A2

has used formulations and yes/no questions for Olle to confirm or reject, Olle's SLP uses

declaratives, based on Olle’s and her own mutual history of therapy. These declaratives can be aligned with, or rejected, by Olle in a similar fashion to formulations and yes/no questions. The uses of declaratives also lead to initiatives by Olle, where he contributes to the collaborative account of the experiences of working with MIT.

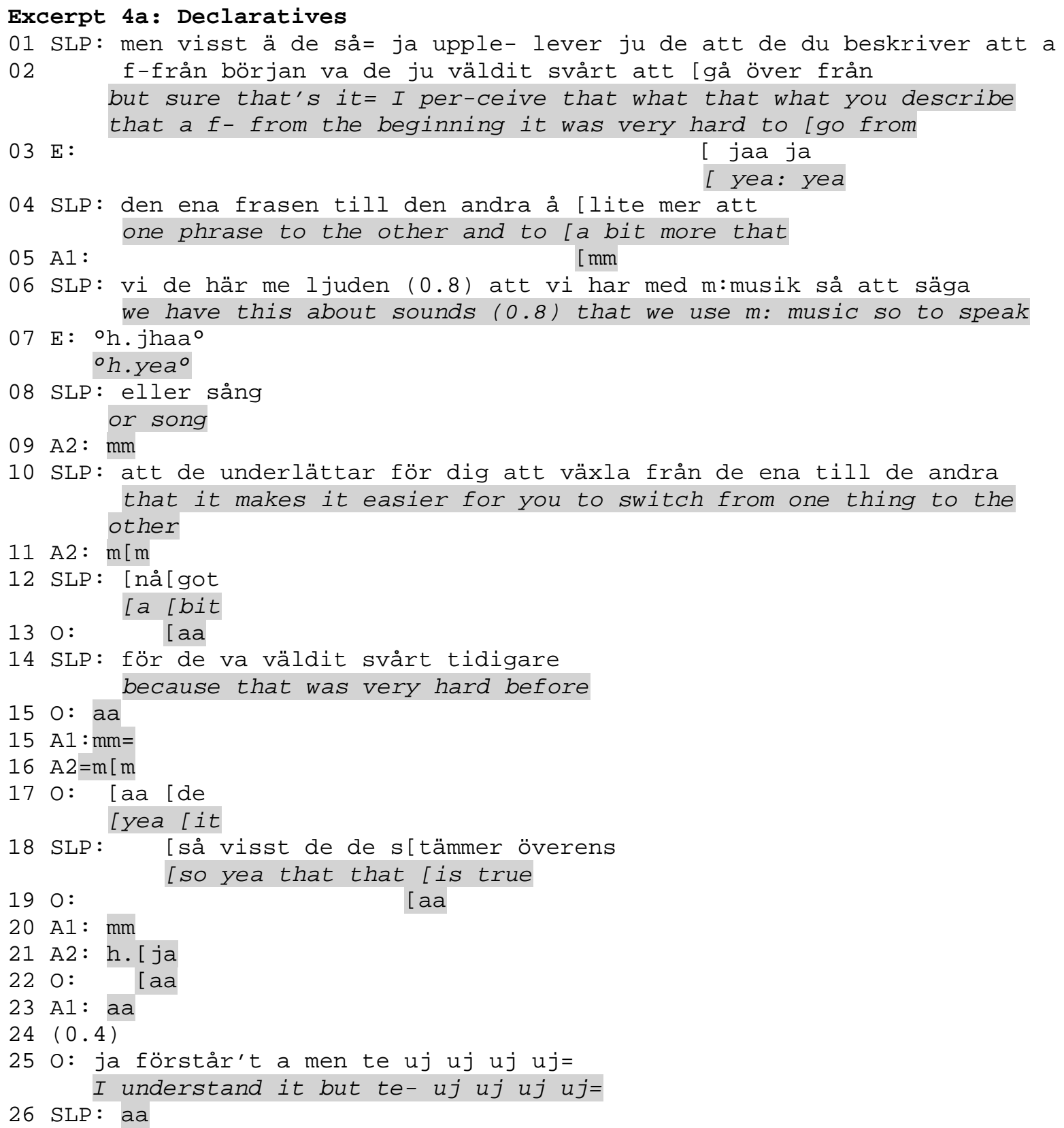


Published in Clinical Linguistics and Phonetics

http://www.tandfonline.com/action/doSearch?AllField=Plejert\&SeriesKey=iclp20.

Published online 13 Sept. 2016.

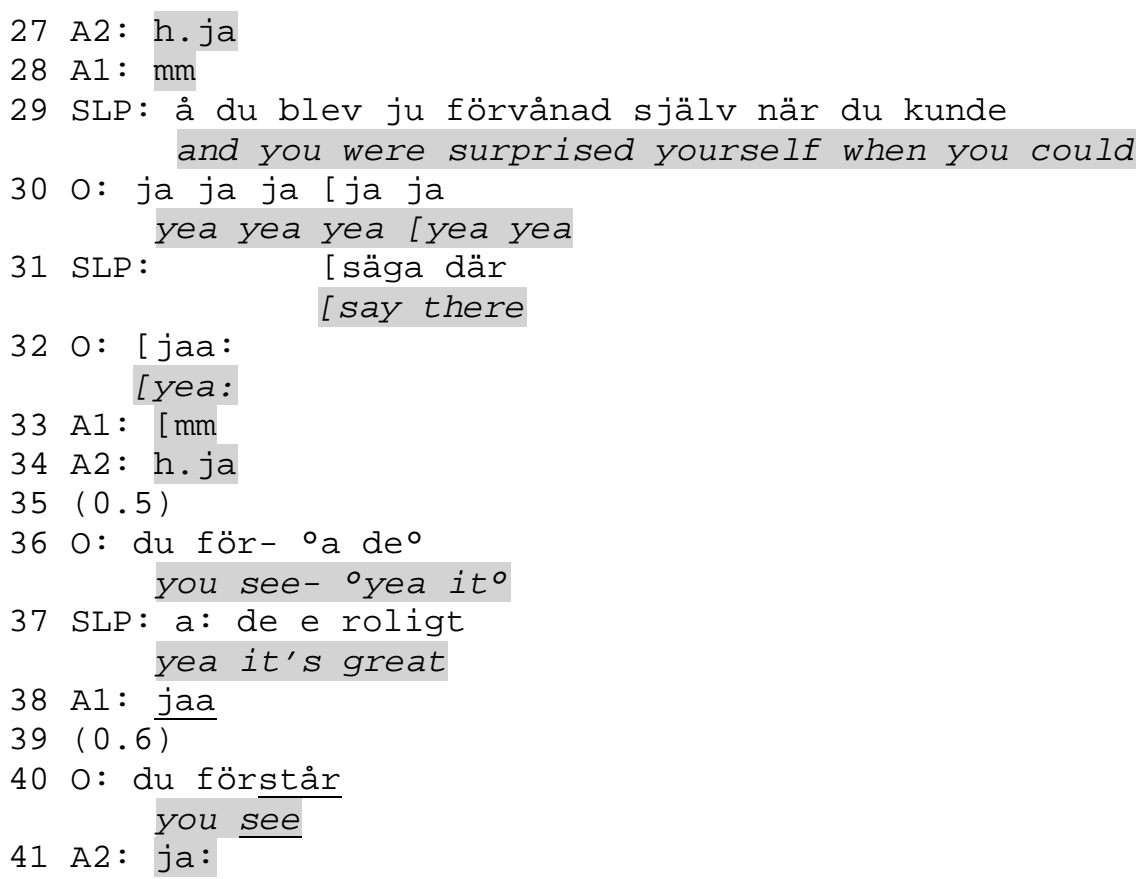

In line 01, the SLP comments on Eva's prior description from the video of the difficulties Olle had had in terms of switching between phrases during MIT. She then comments on the fact that they now work with sounds, music, and song (lines 06, 08), and that this facilitates Olle in switching from one thing to the next to some extent (lines 10,12). In the latter part of her turn, the SLP turns directly towards Olle, subsequent to which Olle accepts the scenario that has just been described (line 13). The SLP continues referring to the fact that it was previously difficult to switch (line 14), again a statement with which Olle agrees (lines 15, 17). She then states that their viewpoints of the usefulness of the method appear to concur (line 18). Again, Olle provides repeated alignment tokens (lines 19, 22) in overlap with the feedback of A1 and A2 (lines 21 and 23). A pause (line 24) indicates that this could have been a potential closure of the topic. However, Olle decides to continue talking, using some of the fixed phrases that come easy to him, produced with some emphasis (line 25). This is picked up by the SLP, who continues in what becomes a collaborative description of the moment in which Olle had managed to switch (line 29 and 31). This declarative is aligned with as Olle enthusiastically displays his agreement (lines 30 32). A1 and A2 display their listenership (lines 33, 34) and 
Published in Clinical Linguistics and Phonetics

http://www.tandfonline.com/action/doSearch?AllField=Plejert\&SeriesKey=iclp20.

Published online 13 Sept. 2016.

then Olle produces a comment "du för-" (you see- ${ }^{\circ}$ yea $i t^{\circ}$ ) (line 36) that is syntactically incomplete, but consists of parts of the fixed phrases that he regularly utilizes as a response, often also produced in a keen tone of voice. The SLP comes in again, with a general comment on how great it is that Olle's ability to switch has improved (line 37), which again is aligned with by Olle.

To use declaratives in describing a mutual experience seems here to be an efficient means for making Olle engaged in the talk, and turns into what may be described as an instance of mutual story-telling by the SLP and Olle, in coordination. The timing of Olle's confirmatory expressions is very precise, and sometimes they also occur in overlap with the SLP's declaratives. This use of continuers, and how they work as encouragement for the nonaphasic speaker to carry on, is quite similar to observations made by Simmons-Mackie et al. (2004). Olle also takes initiatives to continue at points of turn transition (e.g. lines 25, 36), and his turns are picked up by the SLP and treated as part of their common story (lines 29, 37). Again, epistemics (e.g. Heritage, 2013) in terms of shared knowledge and experiences seem to play an important role in making it possible for participants to speak on someone's behalf, as the SLP partly does here. However, even if declaratives are used, Olle does have the ability to disagree or reject them. Here, however, he quite enthusiastically contributes to their mutual story, using prosodic cues such as stress and emphasis to highlight his alignment.

It has previously been shown how the use of formulations, yes/no questions, and declaratives may lead to confirmatory and aligning engagement by Olle. However, these means also allow Olle to express when something is NOT interpreted in accordance with his viewpoints. The fact that he is able to demonstrate when his interlocutors have misinterpreted him, or displayed understandings that he does not find satisfactory, makes his viewpoints come across. This is illustrated in excerpt $4 \mathrm{~b}$ below, which is talk that occurs a few turns after what was described in excerpt 4a above. 
Published in Clinical Linguistics and Phonetics

http://www.tandfonline.com/action/doSearch?AllField=Plejert\&SeriesKey=iclp20.

Published online 13 Sept. 2016.

Excerpt 4b: Declaratives, formulation, and hint-and guess strategies

55 SLP: å så [börja vi me de and so [we started with that

56 0: [nä

57 SLP: å så lös- a så blev de ju så mycket bättre

58 A1: aa and then it sol-yea and then it became so much better

59 A2: $\mathrm{mm}$

60 0: du förstår you see

61 A1: aa

62 A2: h.m

63 0: du fö- nämen uj uj uj

64 SLP: h.ja= you $s$ - but uj uj $u j$

65 A2: $=h . j a=$

66 A1: $=m m$

67 0: du förstår alltså vet du att där å där [(xx) you see well you know that there and there $[(x x)$

68 SLP:

$69(0.7)$

[jaa

70 0: där å där å där $(0.2)$ å fy [faan

there and there and there (0.2) and [damn

71 SLP:

[att du kunde säga flera (.) fra[ser

[that you could say more (.) phra[ses

720 :

73 men ja men sen där å där å där du förstår de e

$74(0.2)$

but yea but then there and there and there you see it is

$[j a$

75 SLP: eh (0.3) menar du att du ä på många ställ[en eh (๑.3) do you meant that you are in many plac[es

760 :

77 de ae ae ae $(x x[x x x)$ du vet

and damn that yea yea $(x x[x x x)$ you know
[YEA
[(( $0:$ dä $[r$
the [re laughter $))$
80 SLP: [först(ådde) du va han mena (här nu)
[did you understand what he meant (here now)

$81 \mathrm{E}$ : ja han mena att vi ä på många ställen där men ja tror inte han har

82 nåt emot de $i$ å för sig=

yea he meant that we are in many places there but I don't think that he has anything against that actually=

83 0: =NEJ (0.3) men eh du förstår alltså att där $(0.4)$ du [(vet) =NO (0.3) but eh you see actually that there (0.4) you [(know)

84 A2:

85 gör em- att du använder musiken både [hä: $r$ å-

[ä de att du

[is it that you

860 :

do em- that you use music both [he:re and-

[yea

$87(0.4)$

[eh ((sighs))

88 A2: på afasihuset

$89(1.0)$

in the aphasia house 
Published in Clinical Linguistics and Phonetics

http://www.tandfonline.com/action/doSearch?AllField=Plejert\&SeriesKey=iclp20.

Published online 13 Sept. 2016.

90 0: [a de vete

[a hell knows

91 A2: [näe de kanske de inte ä

[no that's maybe not it

92 SLP: näe

93 A1:

nö

no

94 SLP: va de de att du tycker att du tränar på många olika sätt?

was it that you think that you practice in many different ways?

$950: J A[A \uparrow \quad J A$

$Y E[A \uparrow \quad Y E A$

In the beginning of excerpt 4b, the SLP has just told A1 and A2 how it came that they tried MIT as part of Olle’s treatment, and how it lead to his improvement (lines 55, 57). Similarly to before, Olle uses the phrase “du förstår” (you see) as a means to display his alignment with what the SLP is saying, with an upgrade in the shape of the word "nämen" (but) followed by exclamation words. It should be mentioned that the Swedish term "nämen” (but) is often used to express surprise or astonishment, rather than contrast. How it is to be interpreted depends on prosody, for example emphasis, and also on what other elements it is combined with. Here, it appears to be used as a resource for Olle to express some enthusiasm and alignment. Olle then takes the initiative to develop the topic (line 67), by repeated use of a deictic phrase. Unfortunately, this retrospection session was only audio recorded, so it is not possible to know if this phrase is combined with pointing, which has previously been observed as a frequently used resource by Olle in the interview and in everyday talk. However, the SLP's interpretation of Olle’s contribution in terms of referring to many phrases, suggests that his non-verbal cues indicate some kind of selection. The SLP provides a guess that Olle is talking about being able to produce different phrases (line 71), which is initially confirmed (line 72) but immediately followed by a "men" (but), which signals that he also wants to express something else. The SLP makes another try, requesting confirmation concerning Olle's being in many places (line 75) (which again suggests that he has been pointing in different directions when saying "and there”). This offered understanding is accepted, with some emphasis by Olle (line 76). 
Published in Clinical Linguistics and Phonetics

http://www.tandfonline.com/action/doSearch?AllField=Plejert\&SeriesKey=iclp20.

Published online 13 Sept. 2016.

However, Olle continues talking, and some cues suggest that he is still not entirely satisfied with the interpretations offered so far. This makes the SLP turn towards Eva, to ask if she knows what Olle might mean at this point (line 80). Eva provides her version of Olle’s account, stating that he was referring to different physical places, adding that she does not think he minds (lines 81, 82). This is initially confirmed as correct by Olle, but followed by a "men" (but) that suggests that the interpretations offered so far are still not entirely satisfactory. Now, A2 engages with what may be described as a hint-and-guess strategy (Laakso and Klippi, 1999), asking if it (it referring to Olle’s efforts to convey something) is a matter of using music both in therapy, and at the aphasia house ( an activity centre where Olle goes regularly, and sings in a choir). This suggestion is followed by a rather long pause (line 89) and is not responded to with any enthusiasm or confirmation by Olle, which makes A2 self-correct (line 91). Now, the SLP makes a new try, still departing from Olle’s signal of wanting to differentiate things from each other. This time she asks if it is a matter of him practising in many different ways (line 94), again in the shape of a guess. Now, Olle enthusiastically confirms that this is what he meant (line 95).

What has been shown in this excerpt is that Olle is quite able to take the initiative to develop topics. It is also shown how hint-and-guess strategies of the kind demonstrated here (cf. Laakso and Klippi, 1999), provide opportunities for the person with aphasia to confirm or reject offered interpretations. It should, however, be remembered that not all persons may have the ability, like Olle, to clearly express their point of view, so the usefulness of this strategy may vary from speaker to speaker. For Olle, this seems to be an efficient means for him to be able to get his ideas across, and, in terms of accessing his standpoint on the intervention that he is taking part in, it is successful.

\section{Concluding discussion}


Published in Clinical Linguistics and Phonetics

http://www.tandfonline.com/action/doSearch?AllField=Plejert\&SeriesKey=iclp20.

Published online 13 Sept. 2016.

The aim of this study was to explore interactional practices used by participants that enhanced involvement and engagement of a person with aphasia, Olle, despite his severe communication difficulties. It was demonstrated that numerous practices were beneficial in order to make Olle’s viewpoints come across. Collaborative tellings, formulations, yes/no questions, declaratives, and hint and guesses, were all designed to somehow capture the gist of what Olle attempted to say despite word-finding difficulties, or when he used fixed expressions as interactional resources (e.g. there and there and there or hell if I know). These are strategies that have been described in prior research, too, as beneficial for communication with people with aphasia (e.g. Goodwin, 1995; Laakso and Klippi, 1999). What is positive about these types of practices is naturally the fact that they provide the opportunity to confirm the offered interpretations by means of short acknowledgment tokens such as yes/no/mm, and/or nonverbal cues. It is also possible for the person with aphasia to reject an item, which might then lead to further negotiation until a satisfactory degree of understanding has been reached. Some drawbacks, however, may be associated with these practices. For example, in cases where the interpretations offered are not satisfactory to the person with aphasia, the repeated use of formulations, guesses etc. may lead to lengthy sequences of repair. Extended repair sequences may be frustrating for all participants, since consensus in ordinary conversation is ordinarily managed by repair over three turns (Schegloff, Jefferson and Sacks, 1977). Lengthy repair sequences that perhaps are not resolved may therefore be experienced as socially dispreferred). In addition, since they in most cases emerge from the production problems of the person with aphasia, it may also make this person's communicative inability come too much into focus, which may be face-threatening or intimidating (Milroy and Perkins, 1992). However, in the context of the current investigation, numerous factors speak in favour of these practices. Olle is participating together with his wife, in a context where they have been asked specifically to talk about their everyday communication needs, and to give their viewpoints on Olle's 
Published in Clinical Linguistics and Phonetics

http://www.tandfonline.com/action/doSearch?AllField=Plejert\&SeriesKey=iclp20.

Published online 13 Sept. 2016.

intervention. Olle has worked with his SLP for some time, so they too know each other well.

The common background of the participants facilitates interpretations and guesses that are likely to be close to what Olle might think or mean. As can be observed in the excerpts (2, 3b, 4b), formulations are often confirmed by Olle in the very next turn, or after slight negotiation where Olle has signalled that he is not entirely content with the first offered understanding. Even in a lengthier repair sequence where negotiations take place over several turns, they do not seem frustrating to Olle. Rather, it appears quite important to him that it becomes clear what he thinks about intervention.

A common background and shared experiences also seem to play a vital role in the setting investigated here. As could be observed, it sometimes happened that Olle's wife, Eva, spoke (partly) on his behalf. It should be noticed, however, that Eva used subtle, and empathetic ways of involving Olle, or displaying that she was not speaking for him (Purves, 2009), e.g. referring to her own experience, the way I see it, (Excerpt 2), or turning to Olle addressing him with, you, as she provided an answer, which Olle could then confirm (Excerpt 1). In addition, Eva withdrew from providing an answer when it came to the more precise details about intervention tasks, possibly since that was Olle’s domain of expertise.

Shared experience may also explain the SLP's successful use of declaratives to tell the other participants about the history of Olle’s intervention. In Excerpt 4a, the accounts of the SLP were actively and enthusiastically responded to by Olle, in a very timely fashion, turning the talk into a mutually constructed story-telling, where Olle and the SLP were the ones with primary and mutual knowledge of what had taken place in therapy. This observation is in line with the findings of Simmons-Mackie et al. (2004), who show how cues like continuers and stereotypical phrases may function as encouragement for the person without aphasia to turn into an animator of talk that in fact the person with aphasia has authored. The SLP was also sensitive to an instance where Olle initiated topic development (Excerpt 4b), which 
Published in Clinical Linguistics and Phonetics

http://www.tandfonline.com/action/doSearch?AllField=Plejert\&SeriesKey=iclp20.

Published online 13 Sept. 2016.

subsequently led to negotiations of Olle’s viewpoint on intervention until a satisfactory degree of understanding had been reached.

\section{Clinical implications}

The present study offers practical implications in terms of identifying and demonstrating how collaborative telling, formulations, yes/no questions, declaratives, and hint-and-guess strategies are used in order to enhance the involvement and engagement of a person with aphasia in talk about his speech and language intervention. However, attention should also be paid to sequences of negotiation that turn lengthy, in order to avoid unnecessary frustration or threats to the face (Milroy and Perkins, 1992). Another implication of this study deals with the role of common knowledge, and that speaking on someone's behalf, may not necessarily be something negative, for example in cases such as a spouse of the person with aphasia reporting her interpretation of her husband's communicative abilities, as was the case here. Speech and language intervention is rarely solely the business of the patient only, but equally important for partners, and other people close to them. To capture as much information as possible from all participants to whom intervention and improved communication are relevant, is therefore of great importance. As previous research shows, patient and family engagement in therapy, increases the possibilities for a successful treatment (Sorin-Peters, McGilton and Rochon, 2010).

Although the current study had interactional practices that enhanced the involvement of people with aphasia in interaction as its primary focus, it also aimed to highlight the role of the activities that participants were engaged in.. Here, participants were involved in two activities that directly dealt with capturing aspects of their everyday communication needs, and their viewpoints concerning Olle’s speech and language intervention. This was performed in a semi-structured interview, and also in a retrospection session, where participants watched 
Published in Clinical Linguistics and Phonetics

http://www.tandfonline.com/action/doSearch?AllField=Plejert\&SeriesKey=iclp20.

Published online 13 Sept. 2016.

and discussed video-clips of everyday talk, and of speech and language intervention. These activities in themselves, are important measures to make patients and their significant others engaged and active in influencing the intervention. Even if the current study was not a part of Olle's intervention, our results strongly speak in favour of patient-centred interventions. This can be achieved both in terms of promoting interactional practices, such as the ones presented in this article, but also by offering patients and their significant others to partake in activities like interviews and retrospection sessions that are directly designed to capture their viewpoints and expressed needs. This must not necessarily take the shape of a systematic functional intervention, which is rare in Sweden, but could complement traditional aphasia intervention, making the treatment more patient-centered.

\section{Acknowledgments}

This work was supported by the Swedish Research Council, VR, grant nr 2010-1440. We would particularly like to thank Olle, Eva and Olle's speech and language therapist, and our two research assistants. We are also very grateful to our peers in the Nordic Network of Interaction Studies on Communication Impairment (NISCI), who have provided us with valuable feedback in data-sessions and on earlier versions of this manuscript. Finally, we are indebted to our co-author, friend and colleague, professor Jan Anward, who sadly passed away before this article was entirely completed. His contributions to the manuscript, along with his mentorship during the research project of which this article is a part, have been invaluable.

\section{Declaration of interest}

The authors report no conflicts of interest. The authors alone are responsible for the content and writing of the article. 
Published in Clinical Linguistics and Phonetics

http://www.tandfonline.com/action/doSearch?AllField=Plejert\&SeriesKey=iclp20.

Published online 13 Sept. 2016.

\section{References}

Ahlsén, E. (1995). Pragmatics in Aphasia - an activity based approach. Gothenburg papers in theretical linguistics, 77.

Albert, M.L., R.W. Sparks and N.A. Helm. 1973. Melodic intonation therapy for aphasia. Archives of. Neurology 29: 130-131.

Basso, A. (2010). Natural conversation: A treatment for severe aphasia. Aphasiology, 24, 4:466-479.

Basso, A., and Caporali, A. (2001). Aphasia therapy or the importance of being earnest. Aphasiology, 15, 4: 307-332.

Beeke, S., Beckley, F., Johnson, F., Heilemann, C., Edwards, S., Maxim, J. and Best, W. (2015). Conversation focused aphasia therapy: Investigating the adoption of strategies by people with agrammatism. Aphasiology 29, 3: 355-77.

Beringer, A. , Tönsing, K. and Bornman, J. (2013) The selfdetermined and partner-predicted topic preferences of adults with aphasia. Aphasiology, 27, 2:227-251.

Byng, S. and Felson Duchan, J, (2005). Social model philosophies and principles: Their applications to therapies for aphasia. Aphasiology, 19, 10/11: 906-922.

Coulter, A. (2002). Whatever happened to shared decision-making? Health Expectations, 5: 185-186.

Couper-Kuhlen, E. (1999). Coherent voicing: On prosody in conversational reported speech. In W. Bublitz and U. Lenk (eds) Coherence in Spoken and Written Discourse: How to Create It and How to Describe It, pp.11-32. Amsterdam: Benjamins.

Dalemans, J.P.R., de Witte, L., Wade, D. and van den Heuvel, (2010). Social participation through the eyes of people with aphasia. International Journal of Communication Disorders, 45, 5:537-550.

Eriksson, K. (2015). The supporting conversation partner in disordered communication. Doctoral Dissertation. Gothenburgh University.

Goffman, E. (1981). Forms of Talk. Philadelphia: University of Pennsylvania Press.

Goodwin, C. (1995). Co-constructing meaning in conversations with an aphasic man. Research on Language and Social Interaction, 28, 3: 233-260.

Goodwin, C. (Ed.) 2003. Conversation and Brain Damage. Oxford University Press.

Goodwin, C. 2004. A competent speaker who can't speak: the social life of aphasia. Journal of Linguistic Anthropology, 14, 2:151-170. 
Published in Clinical Linguistics and Phonetics

http://www.tandfonline.com/action/doSearch?AllField=Plejert\&SeriesKey=iclp20.

Published online 13 Sept. 2016.

Goodwin, H. and Goodwin, C. (1986). Gesture and coparticipation in the activity of searching for a word. Semiotica, 62, 1/2:51-75.

Herbert, R., Best, W., Hickin, J., Howard, D. and Osborne, F. (2003). Combining lexical and interactional approaches to therapy for word finding deficits in aphasia. Aphasiology, 17: 1163-1168.

Heritage, J. and Watson, D. R. (1979). Formulations as conversational objects. In G. Psathas (Ed.) Everyday Language: Studies in Ethnomethodology. pp. 123-162, New York: Irvington.

Heritage, J. (2013) Epistemics in conversation. In J. Sidnell and T. Stivers (Eds.), Handbook of Conversation Analysis. pp. 370-394. Boston: Wiley-Blackwell

Hilari, K., Byng, S., Lamping, D and Smith, S. (2003). Stroke and Aphasia Quality of Life Scale-39 (SAQOL-39). Evaluation of acceptability, reliability, and validity. Stroke, 34:1944-1950.

Holt, E. (1996). Reporting on talk: The use of direct reported speech in conversation. Research on Language and Social Interaction 29, 3: 219-245.

Horton, S., Howell, A., Humby, K. and Ross, A. (2010). Engagement and learning: an exploratory study of situated practice in multi-disciplinary stroke rehabilitation. Disability and Rehabilitation, 33 3:270-279.

Jefferson, G. (2004). Glossary of transcript symbols with an introduction. In G. H. Lerner (Ed.) Conversation Analysis. Studies from the First Generation. pp. 13-31, Amsterdam: John Benjamins.

Kagan, A. (1998). Supported conversation for adults with aphasia: methods and resources for training conversation partners. Aphasiology, 12 (9), 816-830.

Kagan, A., and LeBlanc, K. (2002). Motivating for infrastructure change: Toward a communicately accessible, participation-based stroke care system for all those affected by aphasia. Journal of Communication Disorders, 35, 2: 153-169.

Kindell, J. Sage, K., Keady, J. and Wilkinson, R. (2013). Adapting to conversation with semantic dementia: using enactment as a compensatory strategy in everyday social interaction. International Journal of Communication Disorders, 48, 5:497-507.

Klippi, A., Sellman, J., Heikkinen, P. and Laine, M. (2012). Current clinical practices in aphasia therapy in Finland: Challenges in moving towards best practice. Folia Phoniatrica et Logopedica, 64:169-178. 
Published in Clinical Linguistics and Phonetics

http://www.tandfonline.com/action/doSearch?AllField=Plejert\&SeriesKey=iclp20.

Published online 13 Sept. 2016.

Laakso, M. (2015). Collaborative participation in aphasic word searching: comparison between significant others and speech and language therapists, Aphasiology, 29, 3:269290.

Laakso, M. and Klippi, A. (1999). A closer look at the 'hint and guess' sqeuences in aphasic conversation. Aphasiology, 13, 4-5: 345-363.

Lindholm, C. (2008). Laughter, communication problems and dementia. Communication and Medicine, 5, 1: 3-14.

Lindström, J. (2008).Tur och ordning. Introduktion till svensk samtalsgrammatik. Norstedts akademiska förlag.

Linell, P., Hofvendahl, J. and Lindholm, C. (2003). Multi-unit questions in institutional interactions: Sequential organizations and communicative functions. Text, 23, 4: 539571.

Lock, S., Wilkinson, R. and Bryan, K. (2001a). SPPARC: Supporting Partners of People with Aphasia in Relationships and Conversations, Bicester: Winslow Press.

Lock, S., Wilkinson, R., Bryan, K., Maxim, J., Edmundson, A., Bruce, C. and Moir, D. (2001b). Supporting partners of people with aphasia in relationships and conversation (SPPARC). International Journal of Communication Disorders, 36 Suppl, 25-30.

McClain, C. (2005). Collaborative rehabilitation goal-setting. Topics in Stroke Rehabilitation, 12: $56-60$.

Milroy, L. and Perkins, L. 1992. Repair in aphasic discourse: Towards a collaborative model. Clinical Linguistics and Phonetics, 6:27-40.

Purves, A. B. (2009). The complexities of speaking for another. Aphasiology, 23, 7-8:914925.

Rautakoski, P., Korpijaakko-Huuhka, A-M. and Klippi, A. (2008). People with severe and moderate aphasia and their partners as estimators of communicative skills: A clientcentred evaluation. Aphasiology, 22, 12:1269-1293.

Samuelsson, C. and Plejert, C. (2015). On the use of conversation analysis and retrospection in intervention for children with language impairment. Child Language Teaching and Therapy 31, 1:19-36.

Schegloff, E. A., Jefferson, G. and Sacks, H. (1977). The preference for self-correction in the organization of repair in conversation. Language, 53, (1-2): 361-382.

Sherratt, S., Worrall, L., Pearson, C., Howe, T., Hersh, D.,and Davidson, B. (2011). "Well it has to be language related”: Speech- language Pathologists’ goals for people with 
Published in Clinical Linguistics and Phonetics

http://www.tandfonline.com/action/doSearch?AllField=Plejert\&SeriesKey=iclp20.

Published online 13 Sept. 2016.

aphasia and their families. International Journal of Speech-Language Pathology, 13, 4: 317-328.

Sidnell, J. and Stivers, T. (Eds.) (2013). The handbook of Conversation Analysis. WileyBlackwell.

Simmons-Mackie, N.N., Kingston, D. and Schultz, M. (2004). ”Speaking for another”: The management of participant frames in aphasia. American Journal of Speech-Language Pathology, 13:114-127.

Simmons-Mackie, N.N., Kagan, A., O’Neill Christie, C., Huijbregts, M., McEwen, S., and Willems, J. (2007). Communicative access and decision making for people with aphasia: Implementing sustainable healthcare systems change. Aphasiology, 21, 1: 3966.

Simmons-Mackie, N.N., Raymer, A., Armstrong, E., Holland, A. and Cherney, L.R. (2010). Communication partner training in aphasia: A systematic review. Archives of Physical Medicine and Rehabilitation, 91, 12: 1814-1837.

Sorin-Peters, R., McGilton, K.S. and Rochon, E. (2010). The development and evaluation of a training programme for nurses working with persons with communication disorders in a complex continuing facility. Aphasiology, 24, 1511-1536.

Stivers, T., Mondada, L. and Steensig, J. (2011). The Morality of Knowledge in Conversation. Cambridge: Cambridge University Press.

Wilkinson, R. (2007). Managing linguistic incompetence as a delicate issue in aphasic talk-ininteraction: On the use of laughter in prolonged repair sequences. Journal of Pragmatics, 39, 3:542-569.

Wilkinson, R. (2014). Intervening with Conversation Analysis in speech and language therapy: Improving aphasic conversation. Research on Language and Social Interaction. 47, 3:219-238.

Worrall, L., Sherratt, S., Rogers, P., Howe, T., Hersh, D., Ferguson, A., and Davidson, B. (2011). What people with aphasia want: Their goals according to the ICF. Aphasiology, 25, 3:309-322. 